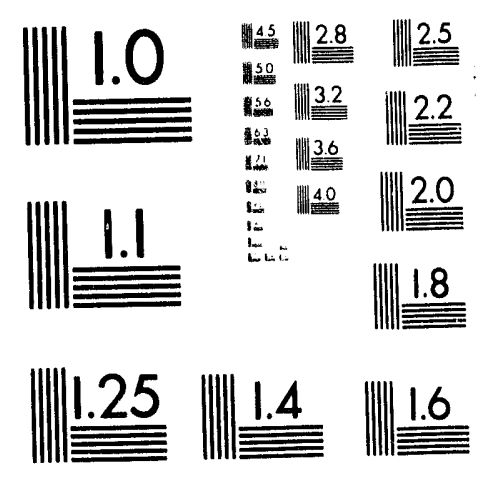



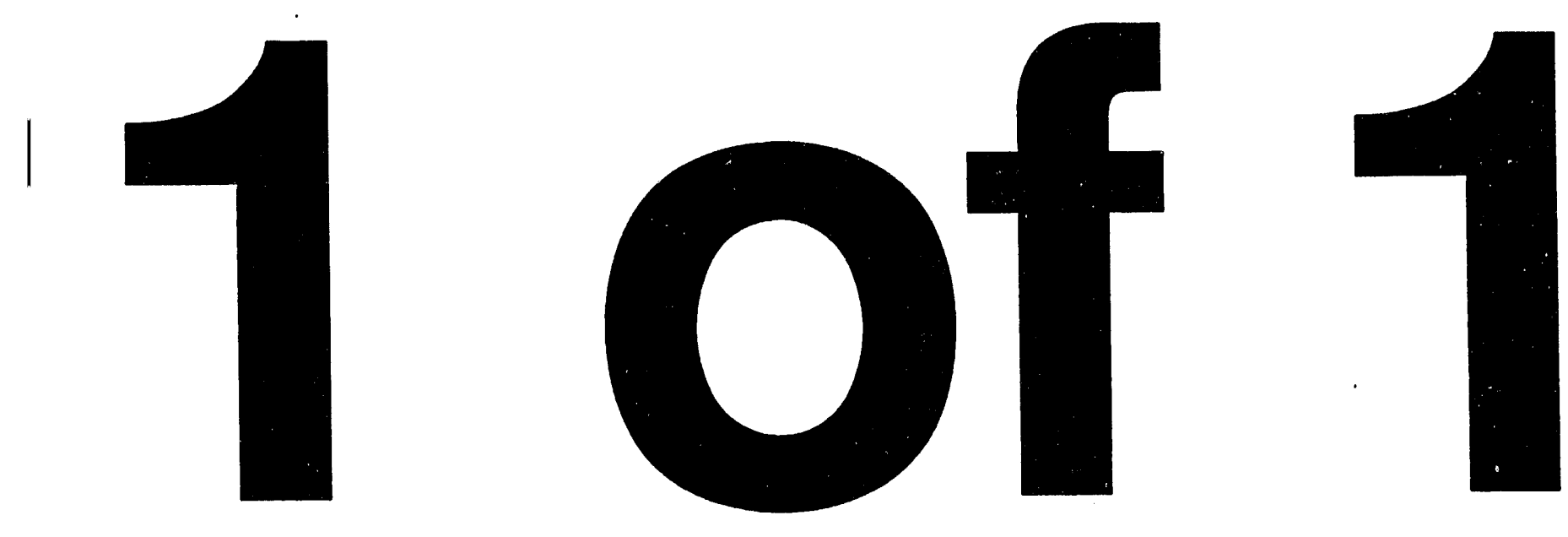


\title{
Crint $131018 \cdots-62$
}

GA-A21494

\section{ARIES-IV NESTED SHELL BLANKET DESIGN}

\author{
by \\ C.P.C. WONG, E. CHEN, C.M. HASAN, K. REDLER, \\ E.E. REIS, S. SHARAFAT, and R. WILL
}

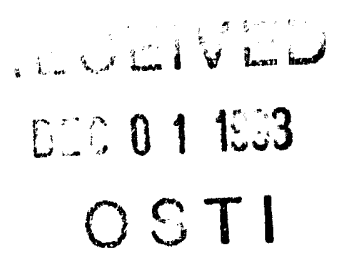

NOVEMBER 1993

OSTI

\section{MASTER}

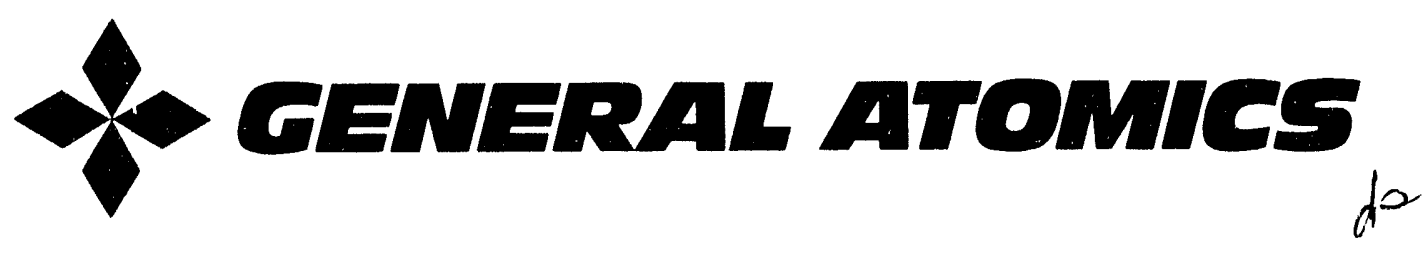




\section{DISCLAIMER}

This report was prepared as an account of work sponsored by an agency of the United States Government. Neither the United States Government nor any agency thereof, nor any of their employees, makes any warranty, express or implied, or assumes any legal liability or responsibility for the accuracy, completeness, or usefulness of any information, apparatus, product, or process disclosed, or represents that its use would not infringe privately owned rights. Reference herein to any specific commercial product, process, or service by trade name, trademark, manufacturer, or otherwise, does not necessarily constitute or imply its endorsement, recommendation, or favoring by the United States Government or any agency thereof. The views and opinions of authors expressed herein do not necessarily state or reflect those of the United States Government or any agency thereof. 
GA-A21494

\title{
ARIES-IV NESTED SHELL BLANKET DESIGN
}

\author{
by \\ C.P.C. WONG, E. CHEN, †C.M. HASAN, ${ }^{\ddagger} K$. REDLER, \\ E.E. REIS, S. SHARAFAT, †and R. WILL
}

This is a preprint of a paper to be presented at the 15th IEEE/NPSS Symposium on Fusion Engineering, October 11-15, 1993, in Hyannis, Massachusetts, and to be printed in the Proceedings.

\author{
Work supported by \\ U.S. Department of Energy \\ Contract DE-AC03-89ER51114 \\ ${ }^{\dagger}$ TSI Research, Inc. \\ $¥$ University of California, Los Angeles.
}

\section{GENERAL ATOMICS PROJECT 3467 NOVEMBER 1993}

\section{GENERAL ATOMICS}




\title{
ARIES-IV NESTED SHELL BLANKET DESIGN*
}

\author{
C.P.C. Wong, K. Redler, E.E. Reis, and R. Will \\ General Atomics \\ P.O. Box 85608, San Diego, California 92186-9784 \\ E. Cheng \\ TSI Research, Inc. \\ C.M. Hasan, S. Sharafat \\ University of California, Los Angeles \\ The ARIES Design Team
}

\begin{abstract}
The $A$ The ARIES-IV Nested Shell Blanket (NSB) Design is an alternate blank blanket concept of the ARIES-IV low activation helium-cooled reactor ditor design. The reference design has the coolant routed in the poloit poloidal direction and the inlet and outlet plena are located at the top and $t$ and bottom of the torus. The NSB design has the high velocity coola coolant routed in the toroidal direction and the plena are located behin behind the blanket. This is of significance since the selected structural ma al material is SiC-composite. The NSB is designed to have key high perfo performance components with characteristic dimensions of no larger than than $2 \mathrm{~m}$. These components can be brazed to form the blanket modu modulc. For the divertor design, we eliminated the use of $W$ as the diver divertor coating material by relying on the successful development of the $\mathrm{g}$ the gascous divertor concept. The neutronics and thermal-hydraulic perfo performance of both blanket concepts are similar. The selected blanket al ket and divertor configurations can also meet all the projected structural, tural, ncutronics and thermal-hydraulics design limits and requirement ments. With the selected blanket and divertor materials, the design has a has a level of safety assurance rate of 1 (LSA-1), which indicates an inher inherently safe design.
\end{abstract}

\section{INTRODUCTION}

I This paper presents the ARIES-IV Nested Shell Blanket (NS (NSB) and divertor designs. These are evolved from the ARI ARIES-I NSB, helium-cooled, SiC-composite, solid breeder blan blanket and divertor designs [1]. The key goals of the ARI ARIES-IV design are to improve the safety rating of the ARI ARIES-I design, which was rated as LSA-2, and to provide mon more details on the configurational and structural analysis of the : the SiC-composite shell design. To improve the safety rating, we : we focused on the selection of blanket and divertor coating mat materials. For the blanket design, in order to eliminate the high highly activated element of $\mathrm{Zr}$, we have replaced $\mathrm{Li}_{2} \mathrm{ZrO}_{3}$ by $\mathrm{Li}_{2} \mathrm{Li}_{2} \mathrm{O}$ as the solid breeder material. For the divertor design, we t we aimed at the elimination of $\mathrm{W}$ as the plasma facing material. al. To meet this objective, we rely on the successful developmer ment of the gaseous divertor design. When the maximum surface face wall loading can be controlled to less than $5 \mathrm{MW} / \mathrm{m}^{2}$ and the electron energy next to the divertor surface hecomes quite low, then $\mathrm{SiC}$ can be used as the plasma facing material. Improvement is also provided in the minimization of the use of Be-metal neutron multiplier. To further understand the use of $\mathrm{SiC}$-composite as the structural material, detailed structural analysis of the more detailed configuration of the SiC-first wall and blanket shells was performed. The design was then completed by performing neutronics and thermal-hydraulics analysis and identifying critical issues.

\section{BLANKET CONFIGURATION}

The configuration of the ARIES-IV NSB design is similar to the ARIES-I nested shell blanket design [1]. More design details are provided in the present study. The differences between the two designs are: the use of separate $\mathrm{Be}$ and solid breeder zones and the use of Be-metal-layer to form a toroidally continuous conducting shell for the purpose of plasma stabilization. The additional use of separate Be and solid breeder zones is to avoid the compatibility problem between $\mathrm{Be}$ and $\mathrm{Li}_{2} \mathrm{O}$ materials.

The ARIES-IV NSB design has the helium plenum located at the back of the blanket zone, and the coolant is routed from the back plenum in the radial and toroidal directions to cool the first wall as shown in Fig. 1. There are 32 outboard and 32 inboard poloidal modules, two per TF coil. The inboard and outboard poloidal modules are composed of 15 and 22 nested U-shape SiC-composite shells, respectively. Schematics of these shells are shown in Figs. 2 and 3. Between the shells we put in the sphere-pac solid breeder and Be neutron multiplier. The helium coolant channels are embedded into each SiC-composite shell, as shown in Fig. 2. The coolant is contained in small diameter $(0.3<\mathrm{d}<0.9 \mathrm{~cm})$ tubes. This design allows the use of high coolant pressure (10 MPa) while using thin wall tubes of $1 \mathrm{~mm}$ thick. In order to provide additional breeding of tritium, the inboard breeder blanket module is extended to cover the back of the divertor as shown in Fig.l. Due to the exponentially decaying distribution of the neutron

*M: *Manuscript received November 11, 1993. This work was supported in part by the U.S. Department of Energy under Contract No. DE-AC03-89ER5III4. 


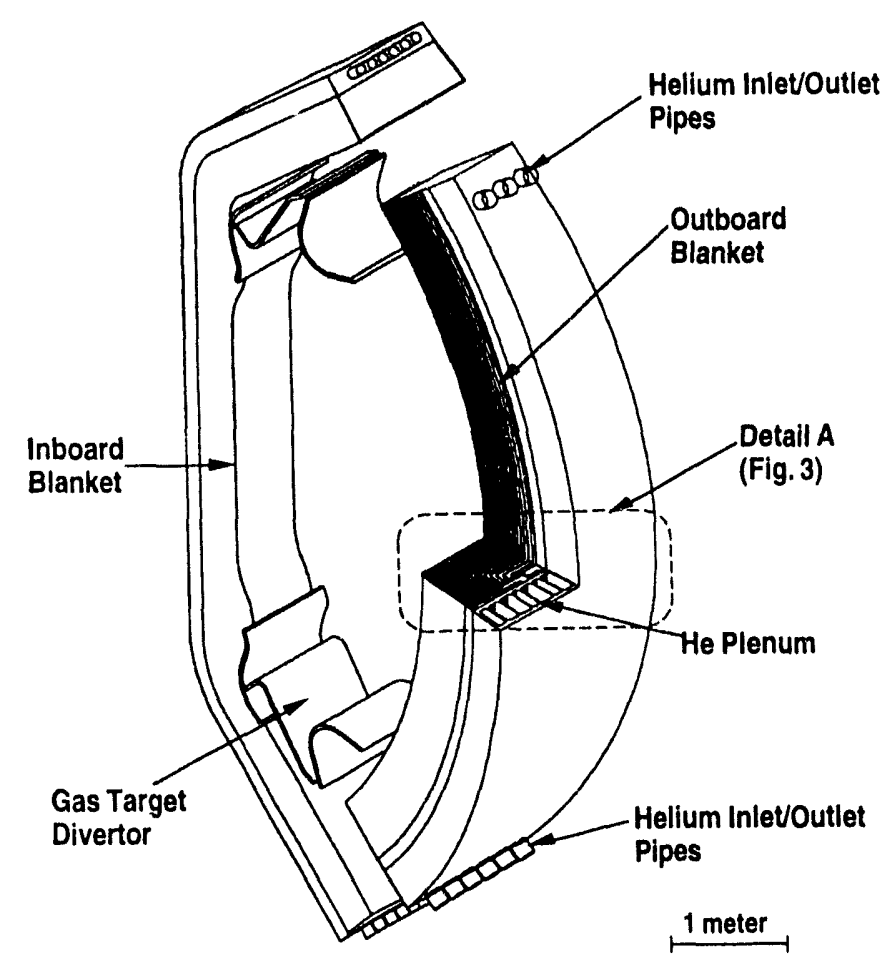

Fig. 1. Nested shell inboard/outboard blankets.

power deposition in the blanket, more power will be gathered at the front zone closest to the plasma, therefore these shells will be closer to each other. The first shell, which is also the first wall, is designed to remove both the nuclear volumetric power and the surface loading from the plasma. Figure 3 also shows that all the structural brazed joints are located at the back of the breeder and neutron multiplier shells zone. The transition zone in the blanket, as illustrated in Fig. 3 is necessary in order to distribute the shell coolant to different channels in the plenum. The heavily structured transition and plenum zones act as the anchor to the more delicate nested shells and also function as neutron reflector and shield.

Based on the nested shells configuration we can see from Fig. 2 that pre-formed U-shape shells can be fitted into the grooves of the reflector/plenum assembly, one layer after another to form the poloidal module. Additional internal supports can be added as needed. The sphere-pac materials can then be poured between the designated shells.

\section{PLASMA STABILIZATION SHELL DESIGN}

For the ARIES-IV solid breeder design, Be-metal spherepac is needed in the outboard shell behind the first wall to provide adequate tritium breeding. Coincidentally, in order to satisfy the second stabilized plasma physics requirement of kink stability, an outboard toroidally continuous conducting shell is needed. The Be-metal-layer neutron multiplier behind the outboard first wall can possibly perform this function. Two design requirements will be needed, the first require- ment is to make the Be-sphere-pac into conducting shelis. This can be achieved by raising the temperature of the $\mathrm{Be}$ sphere-pac filled module, as a step in the fabrication process. to the Be-metal sinter temperature. The spheres then permanently connect and form a conducting shell. The second requirement is to provide toroidal electrical continuity between modules. For this ARIES-IV NSB design, this second requirement can be achieved by making electrical connections at the back of the blanket. The conducting path is from the first wall to the side-wall of the module and then connected through the transition and the plenum zones to the back of module. Between modules, the conducting path can be maintained by Al-alloy metallic connectors. To maintain the feature of low activation design, the electrical conductors in the transition and plenum zones can be made from graphite fiber ropes or strips. This would be viable since the neutron flux in these back zones is much reduced, where the radiation damage to graphite fiber may be acceptable.

\section{NEUTRONICS}

Based on the configuration described above and as shown in Figs. 1 to 3, the neutronics design was performed. The goals for the neutronics calculations were to specify the necessary minimum blanket and shield thicknesses to provide adequate tritium breeding and shielding of the superconducting magnets; and to minimize the use of metallic $\mathrm{Be}$ as the neutron multiplier. 1-D cylindrical geometry calculations based on both a major-radius toroidal model and a minorradius poloidal model were performed. We found that a tritium breeding ratio of 1.1 can be achieved with the combination of $\mathrm{SiC}$-composite material, $\mathrm{Li}_{2} \mathrm{O}$ solid breeder and Be-metal neutron multiplier. The blanket energy multiplication is relatively low at 1.06 . We also found that the quantity of Be can be minimized by using it in a thin layer of $1.7 \mathrm{~cm}$ thickness behind the outboard first wall. Only 6 metric ton of Be will be needed. Local power density for the inboard, outhoard and divertor as a function of radial distributions for different blanket and divertor materials were provided for thermal-hydraulics analysis. Additional calculations were performed for induced radioactivities and the generation of helium and hydrogen in the $\mathrm{SiC}$ material. The latter information is used for the assessment of the safety rating of the design, and the estimation of the lifetime of the SiC-composite structural material.

\section{SAFETY RATING}

Based on the materials that we have selected for the ARIES-IV NSB design, safety rating characteriz atlon was performed for the design [3]. Since the high activited mate:ials of the ARIES-I design, $\mathrm{Li}_{2} \mathrm{ZrO}_{3}$ and $\mathrm{W}$, were replaced by $\mathrm{Li}_{2} \mathrm{O}$ and $\mathrm{SiC}$, the ARIES-IV NSB design received a safety rating of LSA-1, which is he highest rating that any blanket design can have, an indication of inherent safety. 


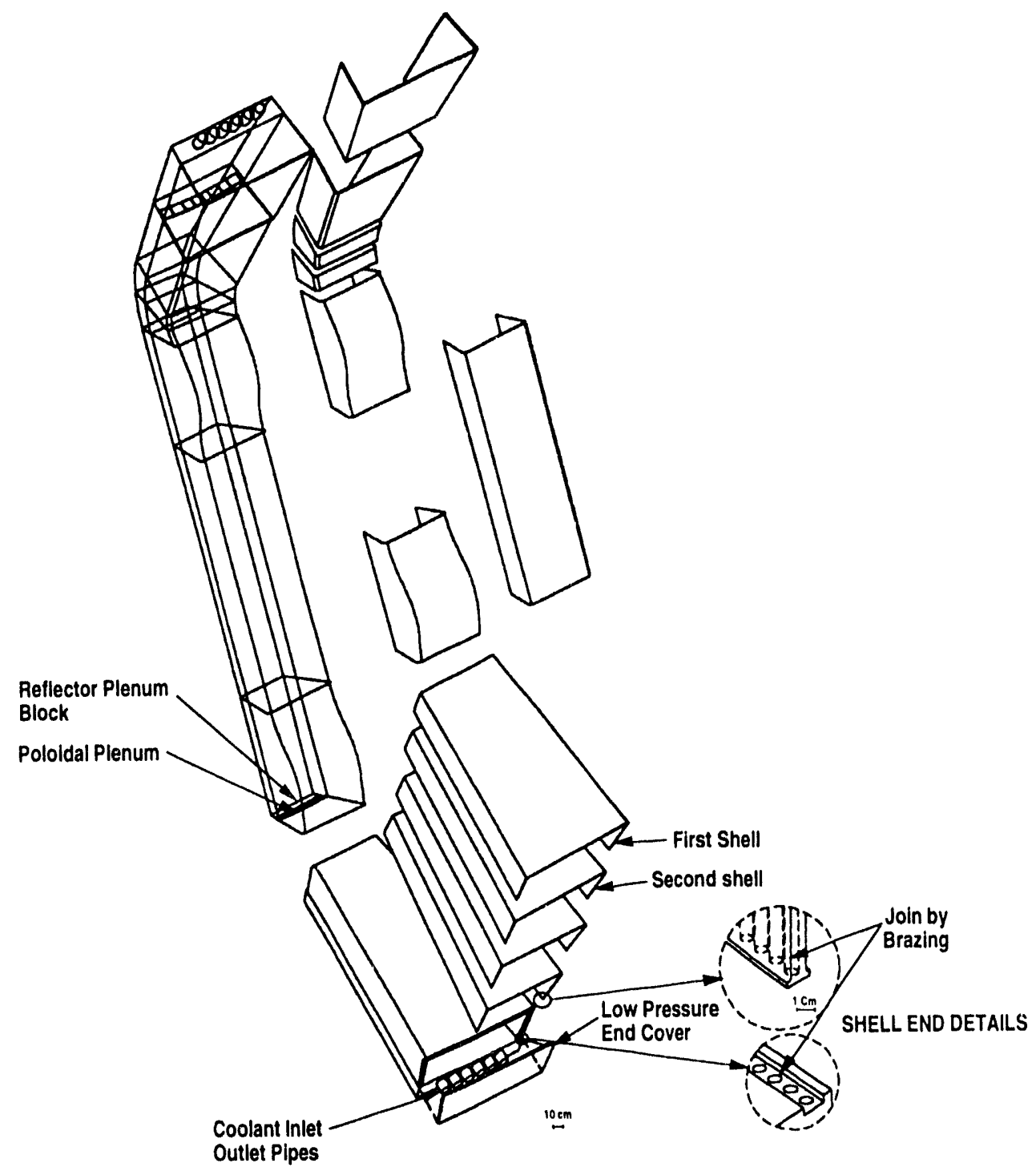

Fig. 2. Assembly schematic of the ARIES-IV NSB design.

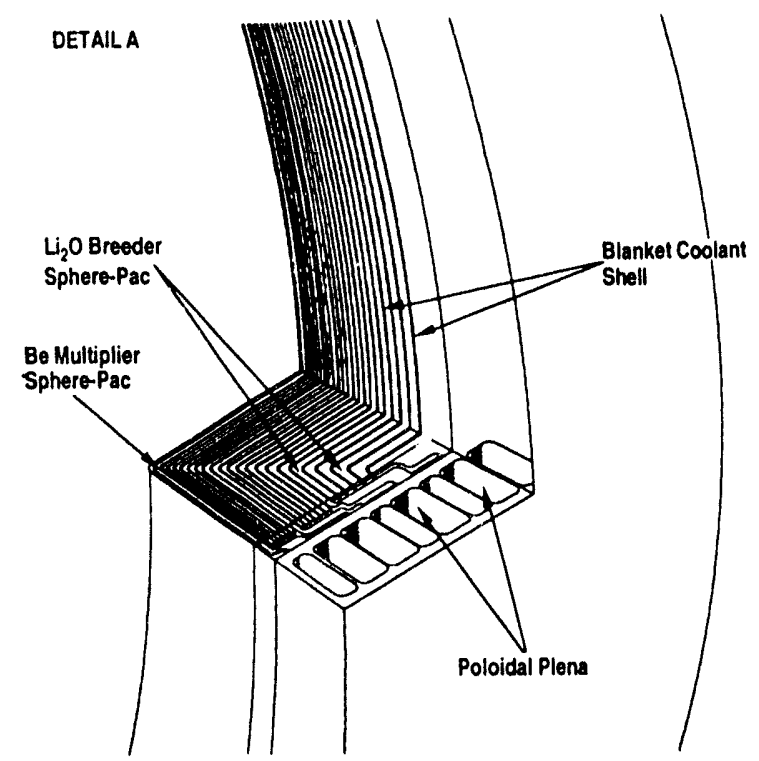

Fig. 3. Cut away of a blanket module.

\section{HEAT TRANSFER AND POWER CONVERSION}

The input parameters that were used to perform the detailed thermal hydraulic calculatons of the ARIES-IV NSB alternate design are presented in Table 1 .

As shown in Table I, at different poloidal locations of the blanket module, the toroidal direction cooling tube can have different dimensions. This shows a design advantage of this ARIES-IV NSB design. This dimensional change is used to adjust to the poloidal neutron and surface heat flux distribution of the design. It also ensures that the toroidal flow in different tubes along the poloidal direction will have similar pressure drop, and thus reduces the complexity of flow control. Based on the nested shell configuration, this change of tube dimension can be accommodated quite easily. The total blanket and shield thicknesses for the inboard and outboard are $100.55 \mathrm{~cm}$ and $168.35 \mathrm{~cm}$, respectively.

\section{THERMAL-HYDRAULIC RESULTS}

I-D heat transfer calculations were performed to determine different material temperatures at different locations of the 
Table I

Thermal-Hydraulic Design Input Parameters

Reactor Geometry

$\mathrm{R}, \mathrm{m}$

6.12

$\mathrm{a}, \mathrm{m}$

1.53

Outboard estimated module height, $\mathrm{m}$

6.2

Inboard module height, $\mathrm{m}$

7.7

First wall circular tube diameter

Outboard at midplane, $\mathrm{cm}$

Outboard at top and bottom, $\mathrm{cm}$

Inboard at midplane, $\mathrm{cm}$

Inboard at top and bottom, $\mathrm{cm}$

Channel wall thickness, mm

Blanket total thickness:

Inboard, $\mathrm{cm}$

Outboard, cm

Shield thickness:

Inboard, $\mathrm{cm}$

Outboard, $\mathrm{cm}$

Fusion Power, $\mathrm{MW} / \mathrm{m}^{2}$

Blanket $\mathrm{M}$,

Average neutron wall loading, $\mathrm{MW} / \mathrm{m}^{2}$

Maximum neutron wall loading, $\mathrm{MW} / \mathrm{m}^{2}$

Average surface loading, $\mathrm{MW} / \mathrm{m}^{2}$

Max. surface loading, $\mathrm{MW} / \mathrm{m}^{2}$

Coolant, $10 \mathrm{MPa}$ helium

T-inlet, ${ }^{\circ} \mathrm{C}$

T-outlet, ${ }^{\circ} \mathrm{C}$

Material properties

$\mathrm{SiC}$ thermal conductivity, $\mathrm{W} / \mathrm{mK}$

Breeder pac-bed effective thermal conductivity, $\mathrm{W} / \mathrm{mK}$

Be pac-bed effective thermal conductivity, $\mathrm{W} / \mathrm{mK}$

Pac-bed and surface contact heat transfer coefficient, $\mathrm{W} / \mathrm{m}^{2} \mathrm{~K}$

Large sphere-pac particles, $\mathrm{mm}$

Small sphere-pac particle, $\mathrm{mm}$

inboard and outboard blankets. We found that the SiC-composite first-wall has maximum temperature of $959^{\circ} \mathrm{C}$, and this is less than the $\mathrm{SiC}$ design limit of $1000^{\circ} \mathrm{C}$. This maximum occurs at the inboard midplane. The $\mathrm{Li}_{2} \mathrm{O}$ breeder has a maximum temperature of $969^{\circ} \mathrm{C}$ occurring at the inboard midplane. This breeder tempcrature occurs at inboard midplane and is less than the design limit of $1000^{\circ} \mathrm{C}$. The interface temperature between the $\mathrm{Li}_{2} \mathrm{O}$ and $\mathrm{SiC}$-composite is less than $800^{\circ} \mathrm{C}$. The maximum Be-metal temperature of $854^{\circ} \mathrm{C}$ occurs at the outboard mid-plane of the module. These results indicate the feasibility of the proposed design. The first wall and inboard and outboard blanket pressure drops were calculated to be 456 $\mathrm{kPa}$ and $141 \mathrm{kPa}$, respectively. The total blanket pumping power including the external loop is $53.1 \mathrm{MW}$. The total blanket pumping power fraction is $2.4 \%$, which is quite acceptable.

\section{STRUCTURAL ANALYSIS}

A first order estimate of the thermal and structural behavior of the ARIES-IV NSB was performed using the two dimensional thermal code TOPAZ-2D and the thermal/structural code COSMOS/M. These codes model the first wall and first shell of the outer and inner blankets. Results from the analysis reveal that a spacing of $1.1 \mathrm{~cm}$ is required between the blankets in order to leave room for thermal expansion in the toroidal direction. Also, the first walls of both blankets expand radially at a different magnitude than the first shells. Therefore, the beryllium sphere-pac of the outer blanket should have a gap of $0.15 \mathrm{~cm}$ before thermal expansion, and the inner blanket a gap of $0.06 \mathrm{~cm}$. Moreover, since the inner blanket has almost horizontal top and bottom sections, compression on the beryllium sphere-pac will occur if a space of $0.75 \mathrm{~cm}$ is not left for vertical expansion.

The temperature distribution of the inboard first wall is shown in Fig. 4. This 2-D calculation shows a maximum temperature of $983^{\circ} \mathrm{C}$, which is less than the limit of $1000^{\circ} \mathrm{C}$. The thermal stress distribution of the inboard first wall is shown in Fig. 5. The maximum Von Mises stress is $92.5 \mathrm{MPa}$. The maximum primary stress caused by the helium coolant at 10 $\mathrm{MPa}$ is $98.9 \mathrm{MPa}$ found in the outer first wall. This is less than the upper limit of the allowable primary stress of 140 MPa. Furthermore, based on calculations using the Section III methods of the ASME code for elbows in tubes, the maximum combined primary and secondary stress found in any of the

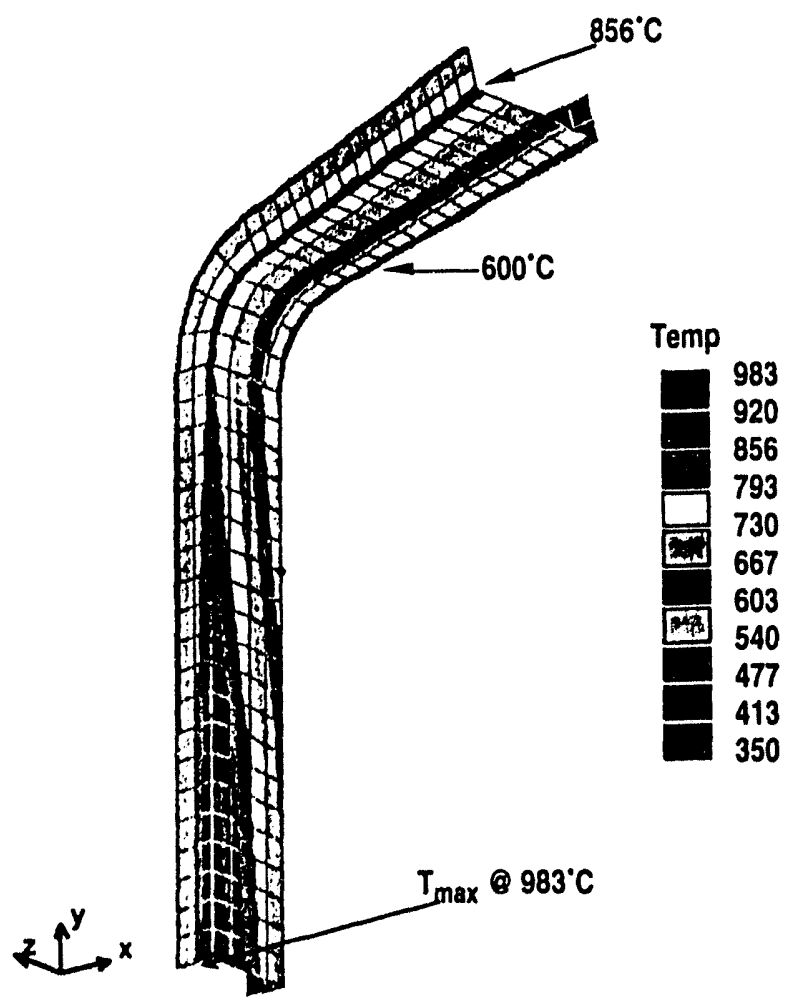

Fig. 4. Temperature profile of inner first wall. 


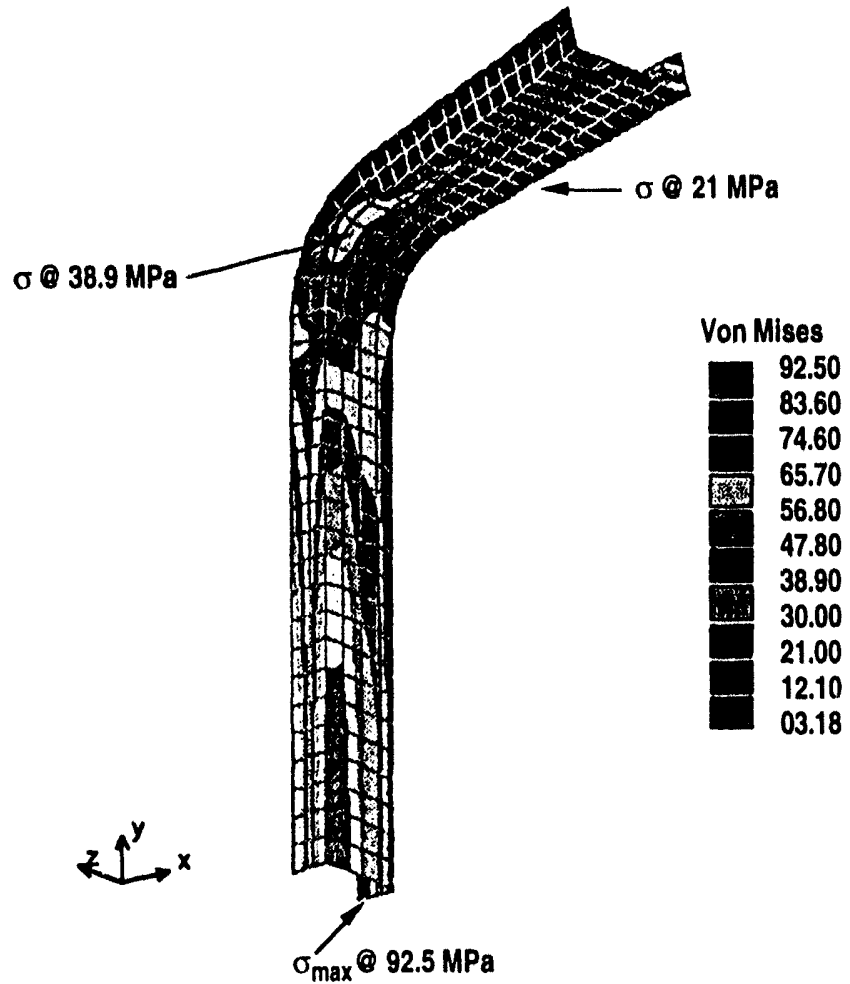

Fig. 5. Thermal-induced stresses inner first shell.

shells is $162 \mathrm{MPa}$, which also occurs in the outer first wall. The allowable for the combination of the primary and thermal stresses is $190 \mathrm{MPa}$. Hence, the design meets the primary and the secondary stress limits of the materials being used.

\section{DIVERTOR DESIGN}

Fig. 1 shows the double null divertor configuration of the ARIES-IV NSB design. Each of the 16 fusion-power core (FPC) modules contains two upper and two lower divertor targets. To fit the geometric requirement of the gaseous divertor approach, each divertor is designed to have three plates: the inboard, middle and outboard plates. The peak heat flux on the gaseous divertor target was projected to be at $5 \mathrm{MW} / \mathrm{m}^{2}$. This heat flux can be removed by smooth tubes or extended surface heat transfer design [1]. The thermal hydraulic design of the divertor cooling system matches the inlet and outlet temperatures of the primary blanket coolant system at the same pressure $\left(350^{\circ} \mathrm{C}\right.$ inlet and $650^{\circ} \mathrm{C}$ outlet). This allows a gross thermal conversion efficiency of $49 \%$ for the blanket and divertor system.

\section{CRITICAL ISSUES}

We have learned from the ARIES-I [1] and ARIES-IV blanket and divertor designs that this combination of coolant, solid breeder and structural material can lead to the most environmentally acceptable fusion reactor design. However. the development of SiC-composite material is still at its infancy. A well coordinated and funded material development program to address the materials related critical issues will be needed. For SiC-composite, these are in the areas of developing leak tight components, and the joining and fabrication of large components. The development of the joining of SiCcomposite to an external high pressure metallic piping system will also be necessary.

The verification of the gaseous divertor design is paramount, since it determines the feasibility of removing surface heat flux by helium coolant and the utilization of low activation material for the divertor surface and components.

It is also very important to verify the adequacy of using the sintered beryllium sphere-pac zone as the stabilization shell for the plasma. If the answer is not supportive of this proposal, it becomes very important to identify an alternate design that will not impact the safety assurance benefit of the present ARIES-IV NSB design.

Other critical issues are in the irradiated sphere-pac material properties, burn-up of structural material, the handling of bred tritium, and the extraction and acceptable routine releases of tritium.

\section{SUMMARY}

The ARIES-IV Nested Shell Blanket (NSB) Design is an alternate blanket concept of the ARIES-IV low activation helium-cooled reactor design. This NSB design has the high velocity coolant routed in the toroidal directions and the plena are located behind the blanket. It is designed to have key high performance components with characteristic dimensions of no larger than $2 \mathrm{~m}$. These components can then be brazed to form the blanket module. All the structural brazed joints are located at the back of the blanket. By relying on the successful development of the gaseous divertor concept, the selected blanket and divertor designs can also meet all the projected structural, neutronics and thermal-hydraulics design limits and performance requirements. With the selected blanket and divertor materials, the design has a safety rating of LSA-1, which indicates an inherently safe design. The key development need of this ARIES-NSB is on the SiC-composite material. Neutron irradiation resistant SiC-composite material that can maintain high performance properties is the key for the successful development of low-activation inherently safe fusion reactor design.

\section{REFERENCES}

[1] F. Najmabadi, et al., "The ARIES-I tokamak reactor Study," Final report, 1991. UCLA-PPG-1323.

12] C. Johnson, Private communication, ANL, 1992

[3] S. Herring, et al., "Safety Analyses of the ARIES-II and ARIES-IV Tokamak Reactor Designs," this conference. 

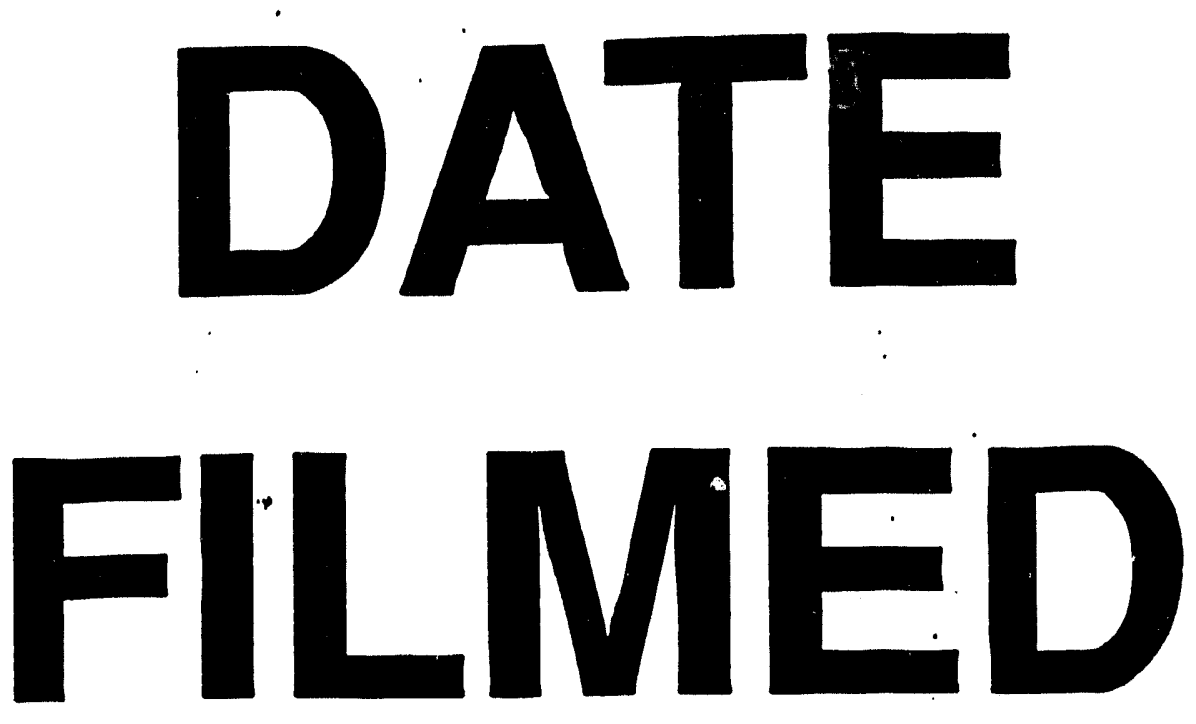

$1 / 21 / 94$
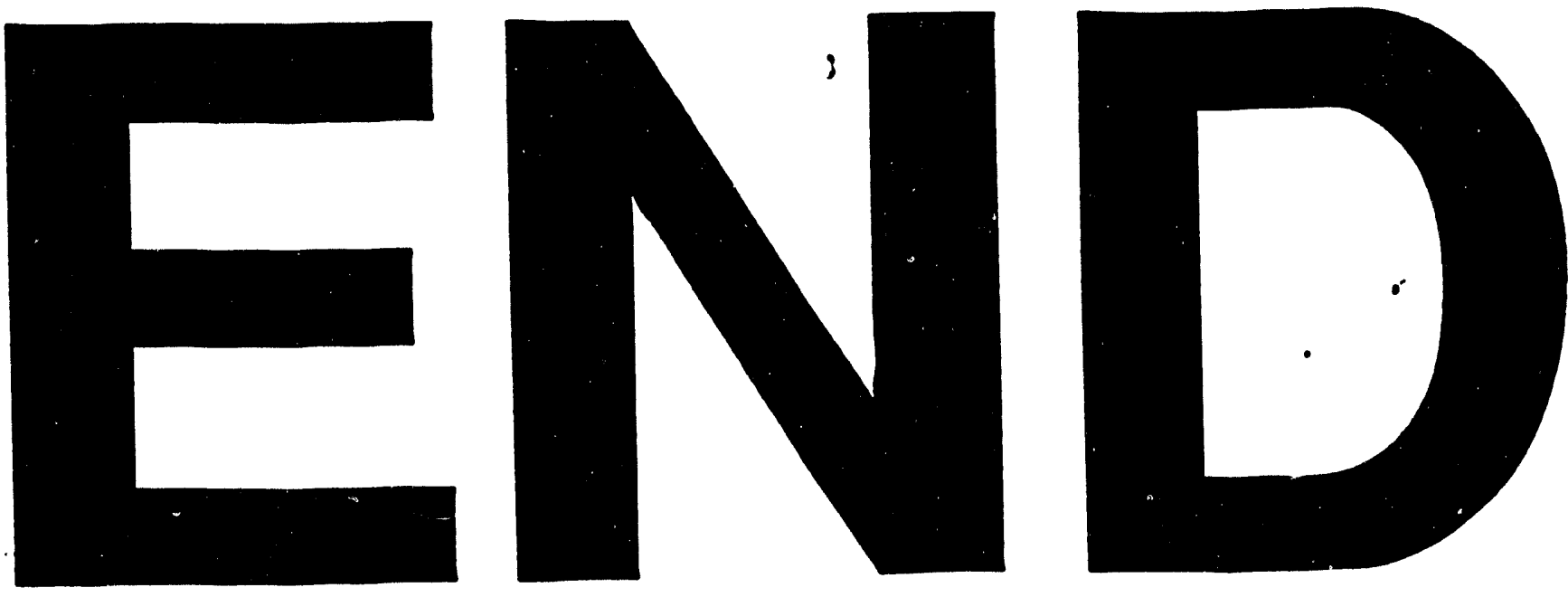
$$
+
$$

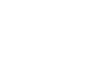

